\title{
Practices of mediatization of consumption in modern russian-language YouTube
}

\section{E. V. Mikhailova ${ }^{1}$}

1Yaroslavl State Pedagogical University named after K. D. Ushinsky, 108/1 Respublikanskaya str., Yaroslavl 150000, Russian Federation

DOI: $10.18255 / 2412-6519-2021-1-66-75$

Research Article

Full text in Russian

Using the concept of "practice of mediatization of consumption", the article analyzes trends in the transformation of consumption in the digital era. The concept of "mediatization of consumption" is compared with the virtualization and commercialization of consumption. The practices of mediatization of consumption are highlighted on the basis of a qualitative analysis of the blogosphere of modern Russian-speaking YouTube and classified in accordance with the basic model of the cycle of individual consumption by R. Blackwell, P. Miniard, J. Angel. Conclusion made on the scale of the spread of media consumption practices and the significant involvement of YouTube users in them. Using examples of specific YouTube channels and video content with a consumer theme, it is shown that by now YouTube has formed and offers users a media environment for implementing a closed cycle of consumption - from the stage of recognizing a product to its public consumption and getting rid of it. It is stated that the widespread occurrence of the phenomenon of mediatization of consumption has created a new context for many Internet users. The peculiarities of this new context are the shifting of the traditional boundaries of privacy, the expansion of the audience watching consumption to an indefinite set. The most important aspect of the phenomenon of mediatized consumption is the possibility of its conversion into financial resources, that is, in essence - the commercialization of consumption.

Keywords: mediatization; mediatization of consumption; virtualization of consumption; commercialization of consumption; practice of mediatization of consumption; consumption model

INFORMATION ABOUT THE AUTHORS

\begin{tabular}{l|l} 
Mikhailova, Elena V. & $\begin{array}{l}\text { E-mail: nmev649@mail.ru } \\
\text { Cand. Sc. (Sociology), Associate Professor }\end{array}$
\end{tabular}

For citation: Mikhailova E. V. Practices of mediatization of consumption in modern russian-language YouTube // Social'nye i gumanitarnye znanija. 2021. Vol. 7, No 1. P. 66-75. (in Russ.) 


\title{
Практики медиатизации потребления в современном русскоязычном YouTube
}

\author{
Е. В. Михайлова ${ }^{1}$
}

1Ярославский государственный педагогический университет им. К. Д. Ушинского, ул. Республиканская, 108/1, Ярославль, 150000, Российская Федерация

DOI: 10.18255/2412-6519-2021-1-66-75

УдК 316.77
Научная статья

Полный текст на русском языке

C помощью понятия «практики медиатизации потребления» в статье анализируются тенденции трансформации потребления в цифровую эпоху. Понятие «медиатизация потребления» сопоставлено с виртуализацией и коммерциализацией потребления. Практики медиатизации потребления выделены на основе качественного анализа блогосферы современного русскоязычного YouTube и классифицированы в соответствии с базовой моделью цикла индивидуального потребления Р. Блэкуэлла, П. Миниарда, Дж. Энджела. Сделан вывод о масштабности распространения практик медиатизированного потребления и значительной вовлеченности в них пользователей YouTube. На примерах конкретных YouTube-каналов и видеоконтента с потребительской тематикой показано, что к настоящему времени интернет сформировал и предлагает пользователям медиасреду для осуществления замкнутого цикла потребления: от стадии узнавания о товаре до его публичного потребления и избавления от него. Констатируется, что широкое распространение феномена медиатизации потребления создало новый контекст потребления для многих интернет-пользователей. Особенностями этого нового контекста являются смещение традиционных границ приватности, расширение аудитории наблюдающих потребление до неопределенного множества. Важнейший аспект феномена медиатизированного потребления - возможность его конвертации в финансовые ресурсы, то есть, по сути, коммерциализация потребления..

Ключевые слова: медиатизация; медиатизация потребления; виртуализация потребления; коммерциализация потребления; практика медиатизации потребления; модель потребления

ИНФОРМАЦИЯ ОБ АВТОРАХ

Михайлова, Елена Валерьевна

E-mail: nmev649@mail.ru

Кандидат социологических наук, доцент кафедры политологии и социологии

Для цитирования: Михайлова Е. В. Практики медиатизации потребления в современном русскоязычном YouTube // Социальные и гуманитарные знания. 2021. Том 7, № 1. С. 66-75.

Видео-контент на тему потребления широко распространен в современном русскоязычном YouTube и вызывает большой зрительский интерес. Блогеры размещают видео с походами по магазинам, кафе, ресторанам, салонам красоты, из туристических поездок, едят и пьют на камеру, устраивают распаковку посылок с заказами из интернетмагазинов, снимают «макияж и наряд дня», делятся своими впечатлениями и оценками по поводу приобретенных товаров, подробно отчитываются перед зрителями о том,

(C) Михайлова Е. В., 2021

Статья открытого доступа под лицензией СС BY (https://creativecommons.org/licenses/by/4.0/) 
что они решили выбросить. Представляется, что подобного рода видео могут быть определены как практики медиатизации потребления.

Медиатизация - междисциплинарный и многоаспектный термин. В исходном смысле это опосредование какого-либо процесса или явления медиа как средствами коммуникации. Впервые термин «медиатизация» был применен английским социологом и исследователем Дж. Б. Томпсоном в работе «Медиа и модернити» в 1995 году [цит. по: 1, с. 195] для обозначения роли медиа как институционально организованных структур, транслирующих не просто информацию, но образцы культуры, формирующие современное общество на протяжении последних веков. Томпсон подчеркивает, что технически медиа имеют ряд специфических характеристик, таких как фиксация символической формы, воспроизведение множества копий, а также пространственновременное дистанцирование. А. А. Гуреева отмечает, что в современной трактовке феномен медиатизации подразумевает процессы опосредования коммуникации и медиавлияние на макросоциальном уровне, в то время как «медиация» характеризует те же процессы на микроуровне [1, с. 200]. Со временем термин «медиатизация» стали применять к широкому кругу объектов: политике, семье, влиянию, войне и т. д. Исследователи приходят к выводу о глобальности процесса медиатизации, что означает его интеграцию во все без исключения сферы общественной жизни и трансформацию этих сфер [2]. Содержание контента таких социальных медиа, как YouTube или Instagram, позволяет говорить о практиках медиатизации потребления.

Под практиками медиатизации потребления понимается медиатизация процесса индивидуального потребления - всего цикла потребления или, что происходит значительно чаще, отдельных его составляющих. Медиатизация потребления в YouTube означает, что процесс потребления намеренно транслируется на неопределенную аудиторию подписчиков и случайных зрителей канала. Демонстрация потребления в видеоблоге - это лишь начальный этап медиатизации, далее демонстрируемые потребительские практики вызывают ответную реакцию зрителей канала в виде комментариев, диалога, вопросов, обмена мнениями, эмоциями. Потребление таким образом перемещается в сферу коммуникаций - становится поводом для общения блогера с подписчиками и подписчиков между собой.

Специфика интернет-платформы YouTube состоит в том, что она является одновременно видеохостингом, где каждый зарегистрированный пользователь может размещать видеоконтент собственного производства, и социальной сетью [3, с. 75]. Исследователи YouTube Джин Берджесс и Джошуа Грин определяют его как новое коллективное медиа. Этими авторами описан такой аспект функционирования YouTube, как «патрон-клиентские» отношения между компанией YouTube и создателями контента (блогерами) [4, c. 6]; они же анализируют YouTube как «массовую культуру участия» [5]. Для анализа медиасреды YouTube можно воспользоваться также теорией поля Пьера Бурдье, рассмотрев YouTube как особое информационное поле, функционирующее по собственным законам [6, с. 107-108]. Особые свойства YouTube как информационному полю придает видеоформат его контента: с одной стороны, оно функционирует как социальная сеть, а с другой стороны - как совокупность средств массовой информации или медиаканалов, создателями которых могут являться видеоблогеры, профессиональные медиа, медийные персоны, разнообразные игроки рынка: рекламные агентства, компании - производители товаров, услуг и т. д.

B настоящее время YouTube - популярное социальное медиа, месячная аудитория YouTube в России в ноябре 2020 года, согласно исследованиям компании Mediascope, составляла свыше 44 млн. пользователей [7]. По данным Mediascope, в феврале-ноябре 2020 года интернетом пользовались 78,1\% населения России старше 
12 лет хотя бы раз в месяц, что составляет около 95,6 млн человек. В среднем за день в интернет выходит 87,1 млн человек, или 71,1 \% населения России. При этом проникновение интернета среди самых молодых россиян- 12-24 года - приблизилось к 100 \%. Среди жителей до 44 лет проникновение превысило 90 \%, а в группе населения 45-54 года интернетом хотя бы раз в месяц пользовались 84,2 \% россиян. Среди самых старших жителей - более 55 лет - интернетом пользовалась лишь половина 49,7 \% [Там же].

Потребление чего-либо «на камеру» или в прямом эфире можно назвать также виртуализацией потребления. Виртуализация потребления и его медиатизация - похожие феномены, однако не идентичные. Уточняя их содержание, можно отметить, что виртуализация потребления может быть частью более масштабного процесса медиатизации потребления. Виртуализация потребления - это относительно новые потребительские практики, в которых потребляемый товар, продукт и сам процесс их потребления возможны только в виртуальном пространстве. Это может быть, например, виртуальная одежда, существующая только на фотографии или видео [8], специальные фильтры и маски-трафареты, преображающие лицо на фотографии [9]. Медиатизация потребления - это не только демонстративное потребление в виртуальной среде, но и тиражирование практик потребления через различные средства коммуникации (прежде всего - социальные сети), инициирование коммуникаций с аудиторией по поводу потребления.

Процесс медиатизации потребления тесно связан с его коммерциализацией: именно через медиатизацию индивидуальное потребление становится способом извлечения дохода для потребителя-блогера. Примером механизма коммерциализации потребления служит потребительская экспертиза товаров и услуг, широко распространенная на различных интернет-ресурсах: в различных социальных сетях и на специальных площадках, где собирают отзывы о товарах, таких как сайты irecommend.ru, otzovik.com, kosmetista.ru. Авторам отзывов на таких сайтах платят, но наиболее существенный доход из рассказа о личном потреблении блогеры извлекают на таких сетевых платформах, как Instagram и YouTube: аккаунты, набравшие определенное количество подписчиков или просмотров, монетизируются, на них размещают рекламу, часть дохода от которой получает блогер. Кроме того, популярные блогеры получают товары на обзор, наиболее успешные вступают в интеграцию с брендами либо пользуются их спонсорской поддержкой. Кроме того, блогеры получают вознаграждение за размещение ссылок на товары в интернет-магазинах под своими видео.

\section{Методы}

Статья основана на качественном описании блогосферы русскоязычного YouTube. Цель исследования - выявить и проанализировать спектр практик медиатизированного потребления, популярных в современном русскоязычном YouTube. Для иллюстрации уровня популярности конкретного YouTube-канала или видео использована статистика количества подписчиков и просмотров отдельных видео на YouTube-канале. Информация о количестве подписчиков и просмотров указана по состоянию на 28 января 2021 года.

Основой классификации видео стала классическая модель процесса принятия решения потребителем, предложенная Р. Блэкуэллом, П. Миниардом, Дж. Энджелом. Модель содержит следующие стадии или элементы цикла потребления товара для индивидуального потребителя: осознание потребности, поиск информации, предпоку- 
почная оценка вариантов, покупка, потребление, оценка вариантов по результатам потребления, освобождение от товара [10, с. 112-131]. Если модель Блэкуэлла, Миниарда и Энджела применить для анализа существующих в русскоязычном YouTube видео с тематикой потребления, можно обнаружить, что практически все стадии процесса потребления за исключением первых двух стадий, которым отдельные видео, как правило, не посвящают, но могут упоминать их вскользь, в контексте прочих тем, широко медиатизированы в специальных жанрово-тематических форматах видео, ожидаемое содержание которых легко распознается аудиторией. Необходимо отметить также, что рассматриваемые стадии процесса потребления находят отражение как в специальных тематических видео, так и в видео с универсально-неопределенной тематикой - влогах ${ }^{1}$ и стримах ${ }^{2}$, когда потребление становится частью общего фона жизни или спонтанным поводом для обсуждения со зрителями в прямом эфире. Задача данной статьи - выделить наиболее популярные жанрово-тематические форматы этих видео, соотнеся их с конкретными стадиями процесса потребления вышеупомянутой модели.

\section{Результаты}

Как уже упоминалась, в современном русскоязычном YouTube медиатизируются практически все стадии процесса потребления, выделенные Блэкуэллом, Миниардом и Энджелом: стадия предпокупочной оценки вариантов, стадия покупки, стадия непосредственного потребления, стадия послепокупочной оценки вариантов и стадия избавления от товара (продукта).

Предпокупочная оценка вариантов широко представлена в русскоязычном YouTube: это различные шопинг-влоги, обзоры магазинов, торговых центров, распродаж. Наиболее распространенный жанрово-тематический формат - шопинг-влог из сетевых магазинов одежды, обуви, аксессуаров ценовых категорий масс-маркет и мидлсегмента. Шопинг-влоги чаще всего снимают блогеры, позиционирующие себя как стилисты или fashion-блогеры. Шопинг-влог начинается обычно со съемки в торговом зале, где блогер указывает на вещи, которые, по его мнению, можно купить, и на те, что покупать ни в коем случае не следует. Затем следуют «луки» из примерочной, собранные из вещей обозреваемого магазина. Наибольшей популярностью у аудитории пользуются каналы известных стилистов: канал «Marianna Eliseeva» (стилист «Модного приговора») с 249 тысячами подписчиков, канал стилиста и телеведущего Александра Рогова «Rogov live» - 188 тысяч подписчиков, канал стилиста Гоши Карцева «goshakartsev» - 219 тысяч подписчиков.

Стадия покупки представлена в основном в жанровом формате видео-распаковки: демонстрируется распаковка посылок с online-заказами; репортажные видео с фиксацией момента offline-покупки встречаются редко. Видео с распаковкой товаров часто содержат примерку вещей. В видео о распаковке товаров блогеры демонстрируют вещи и рассказывают о том, где, по какой цене и зачем они их купили, как планируют носить, с чем сочетать. Если в названии видео заявляется распаковка косметики, отзыв об этой косметике в том же видео, как правило, не предполагается. Названия видео с распаковкой: «мой заказ с сайта ...», «разбираем посылки ...», «много покупок одежда и аксессуары», «распаковка посылок с китайских сайтов», «что я купила на распродажах».

\footnotetext{
${ }^{1}$ «Влог» - сокращение от видеоблога, во влоговом формате видео блогер демонстрирует свою повседневную жизнь: приготовление еды, сборы на работу, магазин, улицу, автомобиль или общественный транспорт, уборку, занятия с ребенком и т. д.

2 «Стрим»- формат видео, в котором блогер ведет диалог со зрителями в прямом эфире, отвечая на их вопросы.
} 
Близкими по содержанию являются видеообзоры offline-покупок: в них могут демонстрироваться косметика, одежда, обувь, аксессуары. В том же самом видео может быть показан процесс перемещения по магазину, общения с продавцом и - достаточно редко - сам момент покупки. Многие блогеры предпочитают снимать два разных видео - из магазина и из дома с распаковкой, предлагая зрителю своего рода интригу для второго видео - «что я все-таки купила?». Относительно недавний тренд русскоязычного YouTube - возросшая популярность обзоров покупок продуктов с демонстрацией чека или с указанием общей суммы покупки: «закупка продуктов на ... рублей», «бюджетные покупки из магазина ..., скидки, акции», «покупка продуктов на неделю (месяц)».

Жанр видео, в котором наиболее очевидным образом медиатизируется стадия непосредственного потребления, - это еда на камеру, или мукбанг. Мукбанг изобрели корейские видеоблогеры около 10 лет назад, постепенно такого рода видео получили распространение и в других странах. Суть мукбанга - поглощение перед камерой большого количества еды при одновременном общении со зрителями. Мукбанг может быть организован в прямом эфире как «стрим» или записан блогером и выложен на канал. Отношение к мукбангу неоднозначное, однако в целом эти видео пользуются значительной популярностью. Популярный русскоязычный мукбанг-блогер - Инна Судакова, канал «Inna Sudakova», количество подписчиков - 190 тысяч. Названия видео мукбанг-блогеров: «Мукбанг. Мясо. Вино. Овощи. Вкусно», «Мукбанг. Очвкусно. Обычная еда», «Мое утро. Кофе. Омлет или яичница?», названия стримов: «Жду вас на кофе», «Решила винишка попить с вами». В период пандемии коронавируса получили значительное распространение zoom-вечеринки или посиделки с друзьями, частью которых стало совместное употребление алкоголя. На YouTube практика «выпивания перед камерой» возникла значительно раньше - блогеры пили в прямом эфире во время стримов, во влоговых видео, появился особый жанр видео «алковлог».

На женских YouTube-каналах закрепились такие жанры медиатизированного потребления, как «outfit of the day» (наряд или образ дня) с подробным рассказом о том, что именно и какого бренда надето, какие использованы украшения, сумка, парфюм; «покупки с примеркой», «макияж дня» или «мой повседневный макияж» с демонстрацией его нанесения, «ежедневная утренняя/вечерняя рутина»- демонстрация процедуры ухода за лицом, «собирайся со мной». Домашним интерьерам и дачным участкам посвящаются видео «room-tour» и «наша дача».

Примером интереса блогеров и зрителей к потреблению одежды другими является жанр видео, который можно назвать «Что надето?». В таких видео блогер подходит к незнакомым людям - как правило, это прохожие на улице - и спрашивает, что на них в данный момент надето. Блогер просит назвать бренд и зачастую цену вещи. Первым на русскоязычном YouTube такие видео стала снимать fashion-блогер с ником «Чума Вечеринка» на канале «Луи Вагон», аудитория подписчиков канала - 395 тысяч. Названия видео с канала «Луи Вагон»: «Во что одеты студенты МГИМО. Лук за 1600000», «Сколько стоит шмот модников в ДЕПО», «Во что одеты модники в Санкт-Петербурге».

Другой вариант медиатизации потребления одежды - streetstyle-видео. В таких видео блогер снимает прохожих на улицах, посетителей торговых центров, кафе, ресторанов, не вступая с ними в диалог. Чаще всего такие видео сопровождаются закадровыми комментариями блогера, который выступает с позиции модного эксперта. В видео блогер, как правило, демонстрирует и собственный «outfit», съемка прохожих в таких видео обычно сочетается со съемкой витрин модных магазинов. Особой популярностью на русскоязычном YouTube пользуются каналы стритстайл-блогеров из Европы: канал «Яна Скворцова» с 207 тысячами подписчиков, которая снимает streetstyle 
в Падуе, Вероне, Венеции; канал «Ella Roma» с 19,8 тысячами подписчиков с видео римских улиц; канал «Marina Mikhina» (214 тысяч подписчиков), на котором есть streetstyle-видео из Санкт-Петербурга, Милана, Венеции. Streetstyle-контент блогеры дифференцируют по тематике, это могут быть: «воскресный streetstyle», «streetstyle из Италии: шубы, пальто, как одеваемся зимой», «как одеваются мужчины в Италии, что носить парню», «как одеваются парижанки в элегантном возрасте».

Примечательна стадия послепокупочной оценки вариантов - в качестве примеров медиатизации этой стадии можно рассматривать многочисленные видео, содержащие потребительскую экспертизу товара, бренда, услуги, магазина. Это различные видеообзоры по группам и категориям товара, брендам, магазинам, салонам красоты. В основе зрительского интереса и доверия к таким видео - опыт личного потребления товара или услуги блогером. На первоначальной стадии существования YouTube приблизительно до начала 2010-х гг. блогерская экспертиза не воспринималась как реклама. Затем началось активное использование потребительской экспертизы как канала и инструмента маркетингового продвижения, в наибольшей степени в таких социальных сетях, как Instagram и YouTube. Пионерами в области потребительской экспертизы на русскоязычном YouTube стали beauty-блогеры. К настоящему времени в сегменте блогерской экспертизы русскоязычного YouTube встречаются рекламные интеграции с брендом на каналах с большим количеством подписчиков и просмотров, видео о товарах, присланных магазином или производителем на обзор у блогеров с более скромным количеством подписчиков. По-прежнему широко распространены и видео с обзорами, снятыми по инициативе самого блогера без сотрудничества с какимлибо брендом, т. е. то, что можно назвать честными и неоплаченными обзорами. Стихийно складывающаяся этика YouTube предполагает, что блогер должен предупредить аудиторию о сотрудничестве с брендом, объявить, что демонстрируемые в видео товары ему прислали на обзор.

Видеообзоры блогеров не только оказывают воздействие на зрителей со сформированной потребностью в товаре или услуге, но и способны вызвать интерес к товару у незаинтересованной аудитории, участвуют в формировании потребностей. В таких видео потребление помещено в общий контекст стиля жизни блогера, его внешности, транслируемого социального статуса, семейной ситуации, речевых особенностей. Воспринимая информацию о товаре, зритель соотносит себя с блогером, оценивает его с точки зрения компетентности, возможности доверять. Некоторые зрители находят в блогерах своего рода ролевые модели или объекты для подражания. Некоторые буквально «заражаются» идеей покупки. Эти социально-психологические факторы способствуют вовлечению зрителей в потребление, формируя потребность как в конкретном товаре, так и в определенном стиле потребления.

Типичные названия видеообзоров: «мои фавориты», «фавориты и разочарования из...», «пустые баночки июня» (или любого другого месяца или года), «что закончилось в ...», «мои уходовые средства», «мои парфюмы» (аналогичные видео есть по любой категории косметических средств), «любимое из люкса», «топ-5 (10) помад» (может называться любая товарная категория), «мои покупки», «что я купила в ...», «что покупать в ...», «бюджетные аналоги люкса», «мой заказ с сайта ...», «что я больше не куплю», «что я повторю», «мои мастхэвы из ...», «что стало с ... после года использования», «покупки (удачные и неудачные) под влиянием YouTube».

Наиболее популярная тематика блогерских обзоров - уходовая и декоративная косметика, парфюмерия, одежда, обувь, сумки, украшения, гаджеты (прежде всего различные модели сотовых телефонов), книги, фильмы и телесериалы, видеоигры, отели, салоны красоты, товары для хобби и рукоделия - вышивки, вязания, шитья, рисования, 
товары для сада и огорода. Относительно новая тематика видеообзоров, которая актуализировалась летом 2020 года, - туристические видео из поездок по российским городам, снятые по принципу «что вижу, о том пою». На содержание блогерского нарратива туристических видео повлияли блоги Ильи Варламова, канал «varlamov» с 2,1 млн. подписчиков. Суть авторской подачи Варламова - критическое описание незнакомого города как объекта для жизни и туризма, т. е., по существу, город также становится объектом потребления. Состояние достопримечательностей, природы, городской инфраструктуры, отелей, кафе и ресторанов, городского транспорта оценивается критически настроенным блогером-наблюдателем прежде всего с точки зрения их реального состояния и комфортности.

Значительный интерес для понимания феномена медиатизации потребления представляет такое популярное, широко представленное на русскоязычном YouTube направление потребительских обзоров, как парфюмерный блогинг. Наиболее популярный русскоязычный парфюмерный канал - канал «Духи РФ»1 с 163 тысячами подписчиков; кроме того, видео с парфюмерной тематикой, как правило, присутствуют на каналах женщин-блогеров beauty и fashion направленности. Трендом последних лет стали мужские парфюмерные блоги, так, например, на канале «Фетишист» 128 тысяч подписчиков. Можно было бы предполагать, что потребительская экспертиза как самовоспроизводящийся и широко доступный в социальных медиа контент будет способствовать повышению уровня требований к товарам и услугам со стороны потребителей и рационализации потребления в целом. Внимательно относясь к выбору товара или услуги, будучи готовым потратить время на поиск информации об интересующем товаре из нескольких, в том числе независимых источников, люди бы покупали только то, что им в наибольшей степени подходит. Вместе с тем популярность видео парфюмерной тематики, которые скорее бесполезны с точки зрения рационального подхода к покупке, поскольку видео не передает запахи, указывает на то, что обращающаяся к блогерской экспертизе аудитория делает это не только для того, чтобы получить объективную оценку товара. Зрители парфюмерных блогеров ищут вдохновения, впечатлений, эмоций, ассоциаций, тем самым по собственной воле вовлекаясь в потребление.

Стадия освобождения от товара представлена в YouTube-блогах такими видео, как «расхламление», «размусоривание», «стильная переделка». В видео о «размусоривании» и «расхламлении» блогеры подробно рассказывают, от каких вещей и почему они решили избавиться, демонстрируют эти вещи. На первый взгляд, внимание к чужому мусору и вещам «на выброс» находится вне здравого смысла и практической полезности, однако количество просмотров у таких видео чрезвычайно велико. Так, видео на канале «Family K» (55,3 тысячи подписчиков) под названием «Расхламление на кухне! До и после! Выкидываю все ненужное» набрало 291201 просмотр, видео с канала «lensky_beauty» (147 тысяч подписчиков) «Выбрасываю люксовую косметику 2021. Косметическая чистка. Расхламление» посмотрели 81974 человека. «Стильная переделка» - перекрашивание старой мебели, «апгрейд» товаров из магазина Фикс прайс и т. д. Популярные русскоязычные каналы о переделке - канал «My DIY life» с 335 тысячами подписчиков, канал «Тanya Leto» - 210 тысяч подписчиков. Названия некоторых видео о переделке: «Красота из мусорного ведра! Идеи декора из стеклянных банок», «Вторая жизнь старых вещей. Переделываю старую посуду», «Реставрация советского Деда Мороза. Как восстановить фигуру из пресс-опилок», «Антикризисные решения. Где применить старые вещи», «Дорогое из дешевого», «Перетяжка старого кресла женскими руками».

\footnotetext{
${ }^{1}$ «Духи PФ». URL: https://www.youtube.com/user/7786463/ (дата обращения: 28.01.2021).
} 
Под видео с потребительской тематикой - с отзывами, распаковкой, обзорами интернет-магазинов - блогеры могут оставлять кликабельные ссылки на демонстрируемые в интернет-магазинах товары. Нередко блогер предоставляет аудитории промокод на дополнительную скидку. Процесс покупки таким образом максимально убыстряется и делается как можно более удобным для потребителя.

\section{Выводы}

Судя по комментариям к видео, у многих зрителей YouTube, особенно среди тех, кто первый раз увидел мукбанг или 15-ти минутную демонстрацию продуктов из магазина «Пятерочка», возникают реакции: «как это вообще можно смотреть?», «это вуаеризм!», «это скучно, неинтересно», «какое мне может быть дело до ваших покупок?». В то же время огромное разнообразие каналов с видео на потребительскую тематику и большое количество просмотров говорят о значительном интересе к такому контенту и массовой вовлеченности пользователей YouTube в практики медиатизированного потребления. Эти практики можно рассматривать как точки пересечения разнообразных потребностей участников медийного поля YouTube. Блогеры снимают такие видео в расчете на коммерческую выгоду. Помимо этого, многих создателей видео-контента привлекает перспектива личной популярности, некоторые очевидно стремятся к демонстративному потреблению на большую аудиторию. Мотивация зрителей также не исчерпывается рациональными потребностями в получении информации о товаре или услуге. На YouTube пользователи восполняют дефицит общения, завязывают новые социальные контакты, удовлетворяют потребности в построении идентичности, референтности. Кому-то просто нравится наблюдать жизнь других. Для кого-то YouTube стал фоном жизни и пришел на смену телевизору. Можно констатировать, что процесс «всеобщей медиатизации» сместил границы приватности и «приличий» доцифровой эпохи. Видеоконтент современного русскоязычного YouTube в полной мере иллюстрирует такие черты общества потребления, как придание потреблению роли смысложизненного ориентира, потребление как основа структурирования времени и повседневности, идентификационная и статусная функции потребления.

Медиатизация потребления посредством YouTube не только опосредует и воспроизводит сложившиеся в доцифровую эпоху практики потребления, но и формирует новые. Речь идет о новом контексте потребления, новой социальной среде, в которой оно реализуется, и о новой ситуации, в которой существует процесс потребления. YouTube напрямую медиатизирует этапы выбора товара, покупки, потребления, послепокупочной оценки и избавления от товара. Две первые стадии потребления в модели Р. Блэкуэлла, П. Миниарда, Дж. Энджела медиатизируются опосредованно. Контент YouTube на тему потребления способствует осознанию потребности в товаре, просмотр такого контента является частью процесса поиска информации. Примечательно, что YouTube как медийное поле самоструктурировался и «встроился» в базовый цикл потребления. Представляется, что в перспективе YouTube или аналогичные ему интернет-платформы способны сформировать новую среду замкнутого цикла потребления: рекламно-информационное поле, магазин, аудиторию для демонстрации приобретенных товаров, площадку для размещения отзывов о товарах и публичного избавления от них.

Социальные и экономические последствия феномена медиатизации потребления многообразны и способны по-разному воздействовать на отдельные социальные группы и институты. Перед маркетингом и рекламой встает очевидная необходимость перестройки системы маркетинговых коммуникаций с потребителем, открываются 
новые возможности таргетирования и установления связей с целевой аудиторией. Для блогеров возникает возможность профессионализации и монетизации потребления, завоевания популярности и символического статуса эксперта. Для многочисленной аудитории интернет-пользователей медиатизация потребления означает его опосредование отзывами блогеров. Важно, что блогерская потребительская экспертиза на YouTube - это не только информативный отзыв о товаре или услуге. Этот отзыв всегда представлен в определенном социальном и личностном контексте и воспринимается аудиторией вместе с особенностями внешности и речи блогера, его манерой самопрезентации, домашним интерьером, информацией о семейном статусе и профессии. В целом можно констатировать, что медиатизация потребления уже сегодня является существенным фактором трансформации таких социальных институтов, как массовая реклама, система розничной торговли, глянцевые модные журналы и элементом повседневности для многочисленной аудитории интернет-пользователей.

\section{Ссылки / References}

1. Гуреева А. А. Теоретическое понимание медиатизации в условиях цифровой среды //

Вестник Московского государственного университета. Серия 10. Журналистика. 2016. № 6. C. 192-208.

2. Livingston S. On the mediation of everything: ICA presidential address 2008 // Journal of communication. 2009. № 59 (1). P. 1-18. URL:

http://eprints.lse.ac.uk/21420/1/On_the_mediation_of_everything_(LSERO).pdf (дата обращения: 28.01.2021).

3. Михайлова Е. В. Beauty-blogging на YouTube как новая медиасреда, опосредующая потребление // Вестник Нижегородского университета им. Н. И. Лобачевского. Серия: Социальные науки. 2018. № 1 (49). С. 75-79.

4. Burgess J., Green J. YouTube: Online Video and Participatory Culture. Cambridge: Polity Press, 2009. 186 p.

5. $\quad$ Burgess J., Green J. Agency and Controversy in the YouTube Community // In: Proceedings IR 9.0: Rethinking Communities, Rethinking Place - Association of Internet Researchers (AoIR) conference, IT University of Copenhagen, Denmark. URL: http://eprints.qut.edu.au/15383/1/153 83.pdf (дата обращения: 28.01.2021).

6. Бурдье П. О телевидении и журналистике / Пер. с фр. Т. В. Анисимовой и Ю. В. Марковой. Отв. ред. и предисл. Н. А. Шматко. М.: Фонд научных исследований «Прагматика культуры», Институт экспериментальной социологии, 2002. 159 с.

7. Mediascope WEB-index // Медиаскоп. Ноябрь 2020. URL: https://webindex.mediascope.net/report?id=88155 (дата обращения: 28.01.2021).

8. Digital clothes are now available in Russia. Do they have a future // Russia Beyond. 14.03.2020. URL: https://www.rbth.com/science-and-tech/331826-digital-clothes-in-russia (дата обращения: 28.01.2021)

9. Вайнштейн О. Everybody lies: фотошоп, мода и тело // Теория моды. 2017. № 43. С. 201-234.

10. Блэкуэлл Р., Миниард П., Энджел Дж. Поведение потребителей. 10-е изд. / Пер. с англ. СПб: Питер, 2007. 944 с. 